\title{
Correspondence
}

GPs' opinions of discharge summaries

Sir: This letter presents findings on general practitioners' (GPs) opinions about psychiatric discharge summaries.

One hundred and sixty-seven questionnaires were sent to all GPs in Coventry, the first part enquiring about the current, and the second part, about the desired format. After one reminder 131 completed forms were returned (78\%).

Summaries sent to GPs were delayed one month (64\%), most of which were too long (53\%). Forty-seven GPs (36\%) complained of their unstructured form and content, and the time spent reading them. The majority of GPs prefer a brief summary (63\%), confined to one page $(71 \%)$ and to reach them within a week of discharge (52\%). The content should highlight diagnosis, medication on discharge and followup arrangements including the name of the key-worker. Some stressed the importance of telephone communication especially in cases of seriously disturbed patients while others suggested psychiatric trainees should spend three months of their training in general practice,

These findings confirm Kerr's opinion that "Abandoning lengthy discharge summaries would lead to reduced boredom on the part of general practitioners and increased clarity of thought among trainee psychlatrists" (Kerr, 1990). It also emphasises the need for effective liaison between the psychiatric services and the primary care providers.

KERR, M. S. (1990) Brttish Medical Journal, S00, 260-261

E. A. ARSANY, St Mary Mental Health Resource Centre, 12 St Mary's Road, Leamington Spa. Warks CV31 1JN

\section{Danger of assault at tribunal hearings}

Sir: In my capacity as responsible medical officer I have recently been the subject of a physical assault by a psychotic patient at her tribunal hearing. The patient concerned was placed next to me and in such a position that I could not escape or obtain any rapid assistance from other mental health professionals present. Thankfully I was able to restrain the patient before she was able to do me any significant harm.

Tribunal or Managers hearings can act as significant stressors for patients and patients may act unpredictably. I wonder whether sufficient attention is given by all concerned as to the potential danger for those present. I would be interested to know whether Members of the College have had any similar experiences. An exchange of thoughts as to the optimal arrangments of such hearings might lead to improvements in safety.

Jo BOWEN, South Kensington \& Chelsea Mental Health Centre, London SW10 9NG

\section{Appropriate placement of dements - lamenting lost opportunity}

Sir: The need for NHS continuing care beds is acknowledged. (Jolley, 1994). When Hollymoor Hospital closed, to serve the east sector of Birmingham (elderly population of 31000 ) we recommended 42 acute admission beds (functional and organic) and 60 continuing care beds. Managers conceded 32 assessment and 24 continuing care beds. They also agreed to invite Coventry Churches Housing Association (CCHA) to provide 36 specialist psychiatric nursing home beds for exclusive use of this population. The CCHA had already established an expertise in this field. As inducement to CCHA, land belonging to the area health authority was given on a 99-year lease for a peppercorn rent, and money given for pump priming. Besides for every bed, a sum of $\$ 70.00$ inflation-proofed was to be given by the area health authority. (The major funding would no doubt come from the patients' estate or Social Security Department). In return the CCHA would take patients only from the old age psychiatry consultants of the east sector of Birmingham.

The facility opened in March 1993. The consultants had hoped that after assessment dements requiring institutional care would be recommended placement in one of five categories of institutions in order of increasing levels of skill input. In ordinary old people's homes (OPH) the skills are restricted to trained 